\title{
Thermochromic Materials for Smart Windows: A State-of-Art Review
}

\author{
Xuanjie Wang and Shankar Narayan* \\ Department of Mechanical, Aerospace and Nuclear Engineering, Rensselaer Polytechnic Institute, Troy, NY, United States
}

Smart windows that regulate solar energy by changing optical characteristics have recently gained tremendous interest for energy-saving and indoor-comfort applications. Among them, thermochromic smart windows are promising because of their simplicity for industrial production and ease of implementation. Although significant advancements have been reported on thermochromic materials, both optical and transition properties remain unsatisfactory. This review focuses on the recent advancement of thermochromic materials for smart windows in terms of operation, performance, and potential for commercialization. It discusses the parameters typically used for gauging performance and provides a summary and comparison of various promising thermochromic materials, including vanadium dioxide, hydrogels, and perovskites. The article also points the challenges in the practical implementation of these materials and provides an outlook for future development.

\section{OPEN ACCESS}

Edited by:

Xiuqiang $\mathrm{Li}$

Duke University, United States

Reviewed by:

Muhammad Sultan Irshad, Hubei University, China

Huaijuan Zhou,

University of Chemistry and Technology in Prague, Czechia

${ }^{*}$ Correspondence: Shankar Narayan narays5@rpi.edu

Specialty section: This article was submitted to Solar Energy,

a section of the journal Frontiers in Energy Research

Received: 23 October 2021 Accepted: 15 November 2021 Published: 08 December 2021

Citation:

Wang $X$ and Narayan S (2021) Thermochromic Materials for Smart Windows: A State-of-Art Review.

Front. Energy Res. 9:800382. doi: 10.3389/fenrg.2021.800382
Keywords: thermochromism, vanadium dioxide, hydrogels, perovskite, optics, smart window

\section{INTRODUCTION}

With population growth and climate change, the rise in energy consumption has become a critical global issue. A significant portion of the energy consumption in buildings is due to heating, ventilation, and air conditioning (HVAC). Numerous studies have focused on materials with tunable optical properties to regulate and convert solar energy for different applications (Li et al., 2020a, Li et al., 2020b; Wang et al., 2020a; Wang et al., 2020b; Wang et al., 2020c). Since windows are substantial sources of heat to the building envelopes, recent investigations on smart windows aim to reduce energy consumption while maintaining thermal comfort for the indoor environment (Khandelwal et al., 2017; Rezaei et al., 2017).

Smart windows are glazed units coated with unique materials to have dynamic control of the transmittance of solar irradiation into buildings under different ambient environments. Typically, based on the glazing characteristics and operation, smart windows can be categorized under actively dynamic or passively dynamic systems. Active dynamic systems change the optical characteristics with an external stimulus, including electricity, mechanical strain, and chemicals (Baetens et al., 2010; Casini, 2018). Passive dynamic systems, on the contrary, respond to a natural stimulus without the input of an artificial external stimulus. Due to the automatic tunability of optical properties without active intervention, smart windows with passive dynamic systems are gaining traction in various applications.

Passive dynamic smart windows can be further categorized according to the respective natural stimulus, including heat, light, and humidity, resulting in thermochromic, photochromic, and humidity-chromic systems. For photochromic windows, a change in the color of constituent materials, including organic and hybrid organic-inorganic dyes, is activated by sunlight $(\mathrm{Wu}$ et al., 2017). On the other hand, humidity-chromic windows are activated by changes in 
ambient humidity resulting in the variation of optical properties (Nandakumar et al., 2018). A temperature variation in the environment naturally triggers the optical properties of thermochromic devices. Lately, significant advancements have been reported on thermochromic smart windows due to their operational simplicity, scalable production, and ease of implementation (Ke et al., 2018; Aburas et al., 2019). While previous reviews on thermochromic thin films provide an insightful discussion on different coating technologies and how they compare with commercial smart windows (Kamalisarvestani et al., 2013; Tällberg et al., 2019), this article focuses mainly on recent advances in thermochromic materials, such as vanadium dioxide $\left(\mathrm{VO}_{2}\right)$, hydrogels, and perovskites.

The optical and transition properties of thermochromic materials are critical to achieving energy savings in large-scale applications. The crucial properties include the transition temperature $\left(T_{c}\right)$, luminous transmittance $\left(T_{\text {lum }}\right)$, solar modulation ability $\left(\Delta T_{\text {sol }}\right)$, color, and durability. The luminous transmittance, $T_{\text {lum }}$ and solar transmittance, $T_{\text {sol }}$ are calculated as shown below (Cui et al., 2018).

$$
\begin{aligned}
T_{\text {lum }} & =\frac{\int_{\lambda=380 \mathrm{~nm}}^{780 \mathrm{~nm}} T(\lambda) V(\lambda) d \lambda}{\int_{\lambda=380 \mathrm{~nm}}^{780 \mathrm{~mm}} V(\lambda) d \lambda} \\
T_{\text {sol }} & =\frac{\int_{\lambda=300 \mathrm{~nm}}^{2500 \mathrm{~nm}} T(\lambda) I_{S}(\lambda) d \lambda}{\int_{\lambda=300 \mathrm{~nm}}^{2500 \mathrm{~mm}} I_{S}(\lambda) d \lambda}
\end{aligned}
$$

The solar modulation ability $\Delta T_{\text {sol }}$ could be calculated as

$$
\Delta T_{\text {sol }}=T_{\text {sol }}^{\text {cold }}-T_{\text {sol }}^{\text {hot }}
$$

Here $\lambda$ is the wavelength, $T(\lambda)$ is the spectral transmittance of the material, $V(\lambda)$ is the photopic luminous efficiency of the human eye, $I_{S}(\lambda)$ is the spectral irradiance of the incoming solar radiation, $T_{\text {sol }}^{\text {cold }}$ and $T_{\text {sol }}^{\text {hot }}$ are solar transmittance at cold and hot temperatures, respectively (Cui et al., 2018).

The following sections summarize and compare the state-ofart thermochromic smart window materials in terms of operation, performance, and future potential. We focus on three groups of thermochromic materials, which include $\mathrm{VO}_{2}$, hydrogels, and perovskites. The fundamental mechanisms and recent performance improvement strategies for thermochromic smart windows are also summarized, along with a future outlook for further development.

\section{VANADIUM DIOXIDE}

Vanadium dioxide $\left(\mathrm{VO}_{2}\right)$ has been widely investigated as a thermochromic material for smart windows due to the reversible metal-to-insulator transition (MIT) at the critical temperature $\left(T_{c}\right)$ of $68^{\circ} \mathrm{C}$ (Goodenough, 1971). At lower temperatures, the monoclinic (M) insulating phase $\mathrm{VO}_{2}$ is infrared-transparent, while at higher temperatures, the rutile $(\mathrm{R})$ metallic $\mathrm{VO}_{2}$ phase is infrared-translucent. The reversible phase transition is related to the atomic structure, charge, spin, and orbital dynamics (Gao et al., 2012; Zhou et al., 2013; Cui et al., 2018). The thermochromic behavior in near-infrared wavelengths makes $\mathrm{VO}_{2}$ an attractive candidate for smart window applications, as shown in Figure 1A. However, several challenges have to be addressed for large-scale applications. As the intrinsic absorption band lies in the visible region, $\mathrm{VO}_{2}$ has a low luminous transmittance in semiconducting and metallic states. In addition, the modulation is typically limited to the near-infrared region, leading to a low $\Delta T_{\text {sol }}$. Besides, a relatively high transition temperature of $\mathrm{VO}_{2}$ (around $68^{\circ} \mathrm{C}$ ) might require heating, which imposes practical limitations for use in buildings.

Many attempts have been made to enhance the thermochromic properties of $\mathrm{VO}_{2}$. Elemental doping with high valence cations (such as $\mathrm{W}^{6+}, \mathrm{Mo}^{6+}$ and $\mathrm{Nb}^{5+}$ ) is a common way to decrease $T_{c}$ by increasing the carrier concentration (Shen et al., 2021). Zhang et al. prepared $\mathrm{W}$-doped $\mathrm{VO}_{2}$ by a hydrothermal recrystallization method (Zhang et al., 2020). A 0.7 at.\% W-doping film shows a suitable $T_{c}$ of $42.7^{\circ} \mathrm{C}$, average $T_{\text {lum }}$ of $61.7 \%$, and $\Delta T_{\text {sol }}$ of $11.7 \%$. Besides, some dopants (such as $\mathrm{Mg}$ and $\mathrm{Ti}$ ) can increase the $T_{\text {lum }}$ due to the widened optical bandgap. As single doping can only improve one of the properties, co-doping with two elements has also been studied. By co-doping $\mathrm{Hf}$ and $\mathrm{W}$ into $\mathrm{VO}_{2}$, Wang et al. modified the thermochromic properties of $\mathrm{VO}_{2}$ alloy films with a $T_{c}$ as low as $38.9^{\circ} \mathrm{C}$, and a $T_{\text {lum }}$ of $41.1 \%$ (Wang et al., 2021).

Other strategies to improve the performance of $\mathrm{VO}_{2}$ include nano- and microscale morphology engineering (Qian et al., 2014; Kim et al., 2019; Schläefer et al., 2019; Wen et al., 2021), the use of anti-reflection coating (Zhou et al., 2016; Liu et al., 2018), porosity tuning (Kang et al., 2011), and multilayered structuring (Long et al., 2016; Sun et al., 2016; Sun et al., 2017). Fabrication complexities and costs associated with the strategies mentioned above may hinder the broader application.

Figure 1A Illustration of thermochromic wood film for smart windows. Adapted with permission from (Liu et al., 2021b), Copyright 2021 American Chemical Society. (B) Schematic of the interaction between hydroxypropyl cellulose, water, and glycerol. Adapted with permission from (Nakamura et al., 2019), Copyright 2019 American Chemical Society. (C) Schematic of switching process of PV smart windows. Adapted with permission from (Wheeler et al., 2017), Copyright 2017 Springer Nature.

\section{HYDROGEL}

Hydrogels are cross-linked hydrophilic polymer chains that swell in water but maintain defined structures. Thermochromic hydrogel undergoes a drastic transmittance change between hydrophilic and hydrophobic states around the lower critical solution temperature (LCST). At temperatures below the LCST, the intermolecular hydrogen bonds connect the polymer chains and water molecules, leading to a hydrophilic property with high transmittance. For temperatures higher than LCST, the polymer collapses due to the breakdown of hydrogen bonds and scatters light, resulting in a hydrophobic state with low transmittance.

The hydrogel is easily fabricated for smart windows with excellent solar modulation. Zhou et al. presented a thermochromic smart window using poly(N-iso-propylacrylmide) (PNIPAm) hydrogel as the active material and investigated the effect of the film thickness (Zhou et al., 2014). For a $52 \mu \mathrm{m}$ thick film, the hydrogel shows a $T_{\text {lum }}$ 


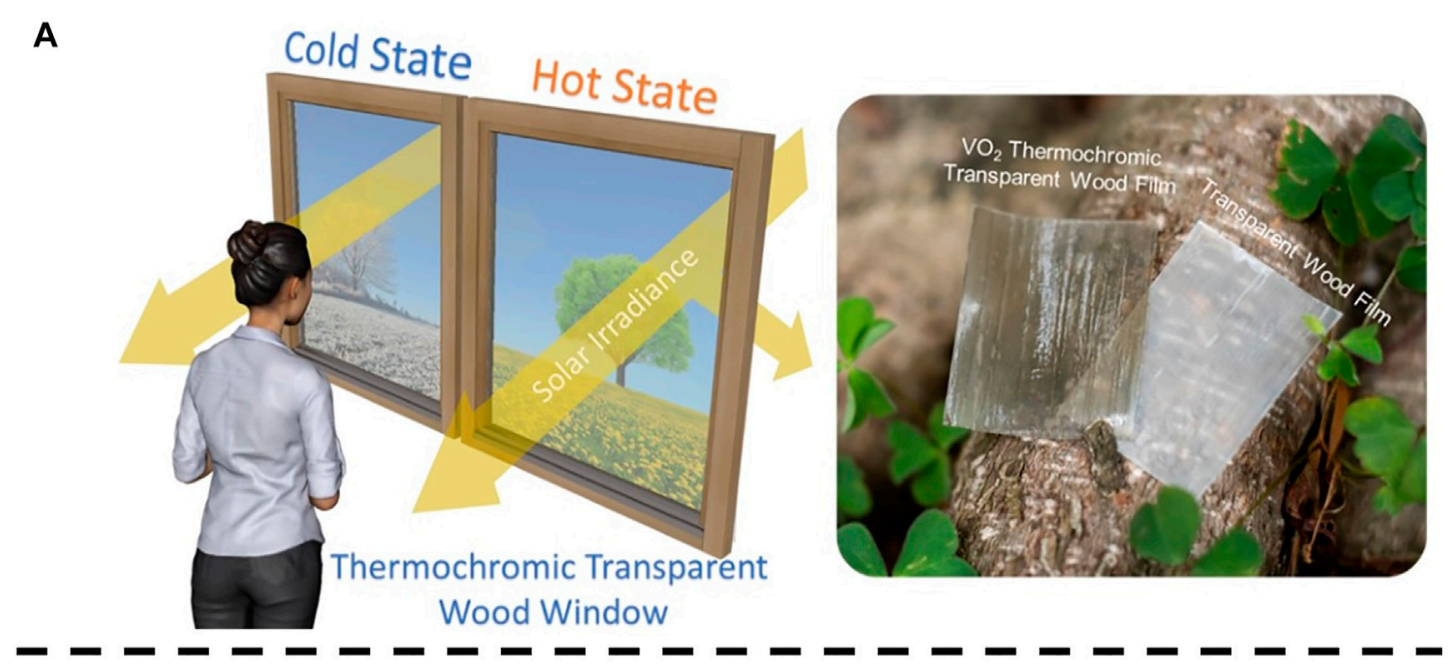

B
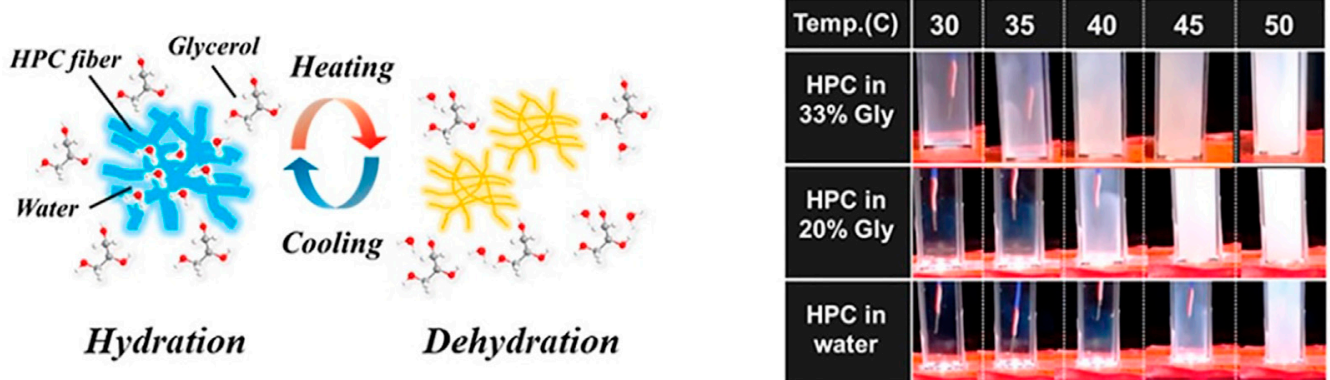

Hydration

Dehydration
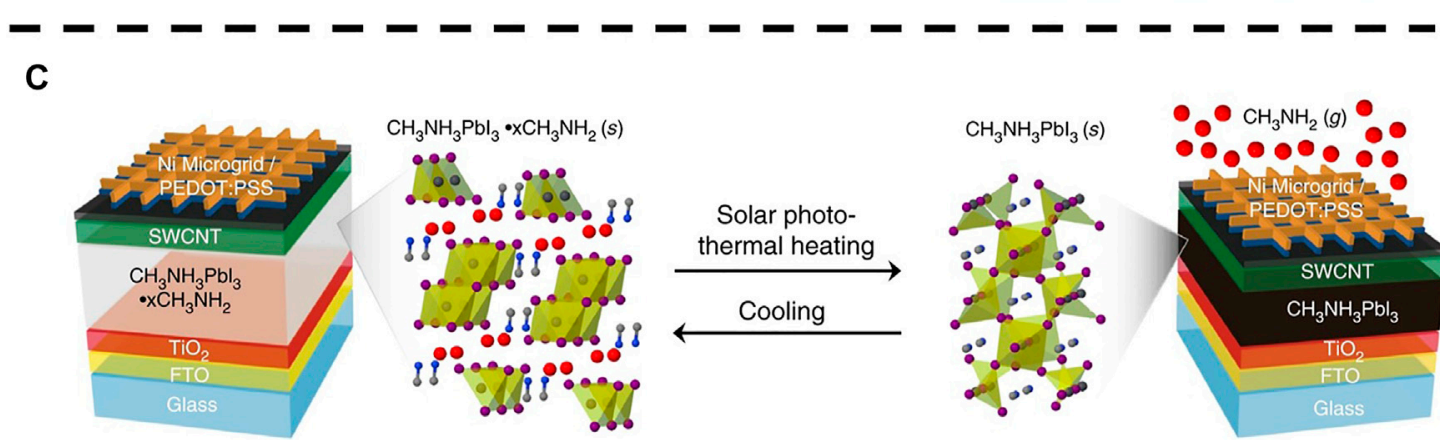

FIGURE 1 | (A) Illustration of thermochromic wood film for smart windows. Adapted with permission from (Liu et al., 2021b), Copyright 2021 American Chemical Society. (B) Schematic of the interaction between hydroxypropyl cellulose, water, and glycerol. Adapted with permission from (Nakamura et al., 2019 ), Copyright 2019 American Chemical Society. (C) Schematic of switching process of PV smart windows. Adapted with permission from (Wheeler et al., 2017), Copyright 2017 Springer Nature.

of 87.9 and $59.9 \%$ at low and high temperatures, respectively, with $\Delta T_{\text {sol }}$ of $20.4 \%$. The scattering behavior of PNIPAm hydrogel can be tuned by modifying the particle size, internal structure, and volume fraction of water. However, size limitations in emulsion polymerization of PNIPAm particles lead to inefficient scattering in the infrared region. To increase the hydrogel particle size and extend the transmittance modulation spectrum in the infrared region, $\mathrm{Li}$ et al. synthesized poly(N-isopropylacrylamide)-2aminoethylmethacrylate hydrochloride (PNIPAm-AEMA) microparticles as a thermochromic material, which achieved a $T_{\text {lum }}$ of $87.2 \%$ with $\Delta T_{\text {sol }}$ of $81.3 \%$ at $\sim 32^{\circ} \mathrm{C}$ ( $\mathrm{Li}$ et al., 2019). The transmittance spectra of a $240 \mu \mathrm{m}$ thick PNIPAm-AEMA varies dramatically when the temperature increases from $31^{\circ} \mathrm{C}$ to $34^{\circ} \mathrm{C}$, indicating a temperature-responsive phase transition. Furthermore, device-level tests show excellent stability with less than a $4 \%$ decrease in infrared transmittance after 1,000 cycles of heating-cooling. In order to adapt thermochromism in cold weather, Nakamura et al. tuned the transition temperature of hydroxypropyl cellulose (HPC) by changing the glycerol concentration, as shown in Figure 1B (Nakamura et al., 2019). Note that, in this case, a rigorous encapsulation strategy is required for practical applications due to the liquid-like characteristics of the hydrogel. 
TABLE 1 | Summary of various thermochromic materials.

\begin{tabular}{|c|c|c|c|c|c|c|c|c|}
\hline Categories & Materials/Methods & $T_{\text {lum }}^{\text {cold }}[\%]$ & $T_{\text {lum }}^{\text {hot }}[\%]$ & $\Delta T_{\text {sol }}[\%]$ & $T_{c}[\mathrm{C}]$ & Advantages & Challenges & Refs \\
\hline \multirow[t]{3}{*}{$\mathrm{VO}_{2}$} & Chemical doping & 61.7 & - & 11.7 & 42.7 & $\begin{array}{l}\text { Implementation, tunable } \\
\text { property }\end{array}$ & $\begin{array}{l}\text { Intrinsic thermochromic limitations, } \\
\text { fabrication complexity }\end{array}$ & $\begin{array}{l}\text { Zhang et al. } \\
(2020)\end{array}$ \\
\hline & Multilayer & 55.4 & 53.9 & 4.3 & 52 & & & $\begin{array}{l}\text { Long et al. } \\
(2016)\end{array}$ \\
\hline & Antireflection coating & 52.7 & 48.7 & 16.4 & 68 & & & $\begin{array}{l}\text { Liu et al. } \\
\text { (2018) }\end{array}$ \\
\hline \multirow[t]{2}{*}{ Hydrogels } & PNIPAm & 87.9 & 59.9 & 20.4 & 32 & Transition temperature & Encapsulation of liquid phase & $\begin{array}{l}\text { Zhou et al. } \\
\text { (2014) }\end{array}$ \\
\hline & PNIPAm-AEMA & 87.2 & - & 81.3 & 32 & Solar modulation ability & & Li et al. (2019) \\
\hline \multirow[t]{4}{*}{ Perovskites } & $\mathrm{CH}_{3} \mathrm{NH}_{3} \mathrm{Pbl}_{3} \bullet \times \mathrm{CH}_{3} \mathrm{NH}_{2}$ & 68 & 3 & - & - & Integrated with PV & $\begin{array}{l}\text { Encapsulation of gas phase, the } \\
\text { safety issue of toxic gas }\end{array}$ & $\begin{array}{l}\text { Wheeler et al. } \\
\text { (2017) }\end{array}$ \\
\hline & $\mathrm{CH}_{3} \mathrm{NH}_{3} \mathrm{Pbl}_{3}$ & 85 & 34.3 & 25.5 & 54.4 & Solar modulation ability & $\begin{array}{l}\text { High transition temperature and } \\
\text { wide hysteresis }\end{array}$ & $\begin{array}{l}\text { Zhang et al. } \\
\text { (2019) }\end{array}$ \\
\hline & $\mathrm{CH}_{3} \mathrm{NH}_{3} \mathrm{Pbl}_{3-x} \mathrm{Cl}_{x}$ & 85.2 & 30.3 & 23.7 & 40.1 & $\begin{array}{l}\text { Narrow transition } \\
\text { hysteresis }\end{array}$ & Long-term stability & $\begin{array}{l}\text { Liu et al. } \\
\text { (2021a) }\end{array}$ \\
\hline & $\mathrm{CsPbl}_{3-x} \mathrm{Br}_{x}$ & 81.7 & 35.4 & - & 105 & Integrated with PV & High transition temperature & $\begin{array}{l}\text { Lin et al. } \\
(2018)\end{array}$ \\
\hline
\end{tabular}

Hydrogel particles with tunable scattering behavior have a promising outlook for further development. Besides, several composites can be created to form multifunctional hybrid hydrogel materials, providing better solar modulation, faster response to stimuli, and enhanced mechanical stability (Zhou et al., 2015a; Zhou et al., 2020).

\section{PEROVSKITE}

Perovskites are materials with a general chemical formula of $\mathrm{ABX}_{3}$, where cations $\mathrm{A}$ and $\mathrm{B}$ are bonded with anion $\mathrm{X}$. Perovskites have been widely applied in solar cells due to their excellent photoelectric properties (Green et al., 2014). Recently, the thermochromic properties of perovskite materials have attracted considerable attention in the smart windows field. It has been found that some halide perovskite materials, with the larger cation A usually the methylammonium ion, the smaller cation $\mathrm{B}$ being $\mathrm{Pb}$, and the anion $\mathrm{X}$ being a halogen ion, exhibit a reversible phase and color change upon a natural thermal stimulus. The thermoresponsive behavior is based on the unique properties of perovskite, including crystallization, gasinduced reaction, and humidity-based hydration/dehydration.

The inverse temperature crystallization (ITC) process in hybrid perovskites was investigated by Saidaminov et al., where the solubility of perovskites in certain solvents decreases with the increase of temperature (Saidaminov et al., 2015). With a careful choice of solvent, temperature, and other parameters, single crystals of $\mathrm{CH}_{3} \mathrm{NH}_{3} \mathrm{PbBr}_{3}$ and $\mathrm{CH}_{3} \mathrm{NH}_{3} \mathrm{PbI}_{3}$ can be rapidly grown with controlled sizes and shapes. Following this pioneering work, De Bastiani et al. utilized the ITC process and tunable optical properties of perovskites to design thermochromic inks for smart window applications (De Bastiani et al., 2017). As the temperature rises from 25 to $120^{\circ} \mathrm{C}$, the inks undergo a color change from yellow to black. However, the solvent needs to be sealed with the ink to achieve the reversible behavior, hindering wider application.

In addition, the gas-induced thermochromic behavior of perovskite has been explored. Zhou et al. reported a reversible phase and color change of perovskite thin films from solid to liquid phase during the perovskite-gas interaction with methylamine $\left(\mathrm{CH}_{3} \mathrm{NH}_{2}\right)$ gas (Zhou et al., 2015b). Wheeler et al. further demonstrated a switchable solar cell device using the low formation/dissociation energy of the methylammonium lead iodide-methylamine complex $\left(\mathrm{CH}_{3} \mathrm{NH}_{3} \mathrm{PbI}_{3} \bullet \mathrm{xCH}_{3} \mathrm{NH}_{2}\right)$, as shown in Figure 1C (Wheeler et al., 2017). In this case, the device switches from a transparent state $T_{\text {lum }}$ of $68 \%$ to an absorbingcolored state $T_{\text {lum }}$ of $3 \%$. Note that the safety issues of methylamine, including flammability and toxicity, need consideration for commercialization.

Humidity-stimulated thermochromic perovskites have also attracted interest. Halder et al. reported a hydrated lead halide hybrid perovskite $\mathrm{CH}_{3} \mathrm{NH}_{3} \mathrm{PbI}_{3}$ with thermochromic behavior under the hydration and dehydration process (Halder et al., 2015). Zhang et al. developed a hydrated $\mathrm{CH}_{3} \mathrm{NH}_{3} \mathrm{PbI}_{3}$ thermochromic window with a $\Delta T_{\text {sol }}$ of $25.5 \%$ and $T_{\text {lum }}$ of 34.3 and $85 \%$ at the hot state $\left(80^{\circ} \mathrm{C}\right)$ and cold state $\left(25^{\circ} \mathrm{C}\right)$, respectively, after optimizing the mixing ratio and spin-coating speed during the fabrication process (Zhang et al., 2019). However, the challenges of relatively high transition temperature and large transition hysteresis need to be overcome. Liu et al. reported a hydrated $\mathrm{CH}_{3} \mathrm{NH}_{3} \mathrm{PbI}_{3-\mathrm{x}} \mathrm{Cl}_{\mathrm{x}}$ thermochromic perovskite smart window, achieving a $T_{l u m}$ of 85.2 and $30.3 \%$ at the cold (room temperature) and hot $\left(60^{\circ} \mathrm{C}\right)$ states, respectively, with a $\Delta T_{\text {sol }}$ of $23.7 \%$ (Liu et al., 2021a).

Further research has shown the potential of integrating both photoactivity and thermochromic features for smart photovoltaic windows applications. Lin et al. demonstrated a smart photovoltaic window using an inorganic halide perovskite, cesium lead iodide/bromide $\left(\mathrm{CsPbI}_{3-\mathrm{x}} \mathrm{Br}_{\mathrm{x}}\right)$ (Lin et al., 2018). At roomtemperature, the transparent non-perovskite phase shows a $T_{\text {lum }}$ of $81.7 \%$, while at elevated temperature $\left(150^{\circ} \mathrm{C}\right)$, the deeply colored perovskite phase exhibits low visible transparency of $35.4 \%$ with high power output. The two switchable phases of perovskite have different optical and photovoltaic efficiencies, making them promising candidates for energy savings. 


\section{CONCLUSION AND OUTLOOK}

In recent years, smart windows have been intensely studied for energy-saving and indoor comfort. This mini-review focuses on the recent advancements of thermochromic materials for smart windows in terms of operation, performance, and potential for commercialization. The performances of promising thermochromic materials, including vanadium dioxide, hydrogels, and perovskites, have been summarized and compared, as listed in Table 1. Reference source not found. Understanding the fundamental mechanisms affecting optical properties and transition and leveraging state-ofart advancements can accelerate the development of energy-saving smart windows.

In order to fill the gap between lab-scale demonstrations and practical applications, further research is needed. This paper suggests further research along three lines: 1) Relative to conventional $\mathrm{VO}_{2}$ materials, emerging materials like hydrogel and perovskite have shown better thermochromic performance. Further research could focus on various strategies for integration, especially for perovskites, which have shown potential for demonstrating several features beyond thermochromism; 2) Besides the three major thermochromic materials discussed in the review, exploring new materials with novel thermochromic mechanisms will help expand the range of potential candidates. For example, ionic liquids, liquid crystals (Jiang et al., 2021), and metamaterials have shown promising thermochromic properties; 3) Finally, the durability and safety of

\section{REFERENCES}

Aburas, M., Soebarto, V., Williamson, T., Liang, R., Ebendorff-Heidepriem, H., and Wu, Y. (2019). Thermochromic Smart Window Technologies for Building Application: A Review. Appl. Energ. 255, 113522. doi:10.1016/ j.apenergy.2019.113522

Baetens, R., Jelle, B. P., and Gustavsen, A. (2010). Properties, Requirements and Possibilities of Smart Windows for Dynamic Daylight and Solar Energy Control in Buildings: A State-Of-The-Art Review. Solar Energ. Mater. Solar Cells 94, 87-105. doi:10.1016/j.solmat.2009.08.021

Casini, M. (2018). Active Dynamic Windows for Buildings: A Review. Renew. Energ. 119, 923-934. doi:10.1016/j.renene.2017.12.049

Cui, Y., Ke, Y., Liu, C., Chen, Z., Wang, N., Zhang, L., et al. (2018). Thermochromic VO2 for Energy-Efficient Smart Windows. Joule 2, 1707-1746. doi:10.1016/ j.joule.2018.06.018

De Bastiani, M., Saidaminov, M. I., Dursun, I., Sinatra, L., Peng, W., Buttner, U., et al. (2017). Thermochromic Perovskite Inks for Reversible Smart Window Applications. Chem. Mater. 29, 3367-3370. doi:10.1021/ acs.chemmater.6b05112

Gao, Y., Wang, S., Kang, L., Chen, Z., Du, J., Liu, X., et al. (2012). VO2-Sb:SnO2 Composite Thermochromic Smart Glass Foil. Energy Environ. Sci. 5, 8234-8237. doi:10.1039/c2ee21119j

Goodenough, J. B. (1971). The Two Components of the Crystallographic Transition in VO2. J. Solid State. Chem. 3, 490-500. doi:10.1016/00224596(71)90091-0

Green, M. A., Ho-Baillie, A., and Snaith, H. J. (2014). The Emergence of Perovskite Solar Cells. Nat. Photon 8, 506-514. doi:10.1038/ nphoton.2014.134

Halder, A., Choudhury, D., Ghosh, S., Subbiah, A. S., and Sarkar, S. K. (2015). Exploring Thermochromic Behavior of Hydrated Hybrid Perovskites in Solar Cells. J. Phys. Chem. Lett. 6, 3180-3184. doi:10.1021/acs.jpclett.5b01426

Jiang, Y., Zhou, Y., Wang, M., and Yang, D.-K. (2021). Smart Thermally Switchable Liquid Crystal Window. Adv. Photo Res. 2, 2000156. doi:10.1002/ adpr.202000156 materials should be considered, especially for materials requiring encapsulation of gas or liquid. The leakage of thermo-responsive materials may lead to a dramatic decline in performance.

\section{AUTHOR CONTRIBUTIONS}

All authors listed have made substantial, direct, and intellectual contribution to the work and approved it for publication.

\section{FUNDING}

This material is based upon work supported by the National Aeronautics and Space Administration under Grant No. 80NSSC21K0072 issued through the Space Technology Research Grants Program.

\section{ACKNOWLEDGMENTS}

The authors acknowledge the support of the National Aeronautics and Space Administration under Grant No. 80NSSC21K0072 issued through the Space Technology Research Grants Program.

Kamalisarvestani, M., Saidur, R., Mekhilef, S., and Javadi, F. S. (2013). Performance, Materials and Coating Technologies of Thermochromic Thin Films on Smart Windows. Renew. Sustainable Energ. Rev. 26, 353-364. doi:10.1016/j.rser.2013.05.038

Kang, L., Gao, Y., Luo, H., Chen, Z., Du, J., and Zhang, Z. (2011). Nanoporous Thermochromic VO2 Films with Low Optical Constants, Enhanced Luminous Transmittance and Thermochromic Properties. ACS Appl. Mater. Inter. 3, 135-138. doi:10.1021/am1011172

Ke, Y., Zhou, C., Zhou, Y., Wang, S., Chan, S. H., and Long, Y. (2018). Emerging Thermal-Responsive Materials and Integrated Techniques Targeting the Energy-Efficient Smart Window Application. Adv. Funct. Mater. 28, 1800113-1800118. doi:10.1002/adfm.201800113

Khandelwal, H., Schenning, A. P. H. J., and Debije, M. G. (2017). Infrared Regulating Smart Window Based on Organic Materials. Adv. Energ. Mater. 7, 1602209. doi:10.1002/aenm.201602209

Kim, K.-S., Son, E.-W., Youn, J. W., and Kim, D. U. (2019). Intense Pulsed Light Sintering of Vanadium Dioxide Nanoparticle Films and Their Optical Properties for Thermochromic Smart Window. Mater. Des. 176, 107838. doi:10.1016/j.matdes.2019.107838

Li, X.-H., Liu, C., Feng, S.-P., and Fang, N. X. (2019). Broadband Light Management with Thermochromic Hydrogel Microparticles for Smart Windows. Joule 3, 290-302. doi:10.1016/j.joule.2018.10.019

Li, X., Sun, B., Sui, C., Nandi, A., Fang, H., Peng, Y., et al. (2020a). Integration of Daytime Radiative Cooling and Solar Heating for Year-Round Energy Saving in Buildings. Nat. Commun. 11, 1-9. doi:10.1038/s41467-020-19790-x

Li, Y., Lin, C., Huang, J., Chi, C., and Huang, B. (2020b). Spectrally Selective Absorbers/ Emitters for Solar Steam Generation and Radiative Cooling-Enabled Atmospheric Water Harvesting. Glob. Challenges 5, 2000058. doi:10.1002/gch2.202000058

Lin, J., Lai, M., Dou, L., Kley, C. S., Chen, H., Peng, F., et al. (2018). Thermochromic Halide Perovskite Solar Cells. Nat. Mater 17, 261-267. doi:10.1038/s41563-0170006-0

Liu, C., Wang, S., Zhou, Y., Yang, H., Lu, Q., Mandler, D., et al. (2018). Indextunable Anti-reflection Coatings: Maximizing Solar Modulation Ability for Vanadium Dioxide-Based Smart Thermochromic Glazing. J. Alloys Compounds 731, 1197-1207. doi:10.1016/j.jallcom.2017.10.045 
Liu, S., Du, Y. W., Tso, C. Y., Lee, H. H., Cheng, R., Feng, S. P., et al. (2021a. Adv. Funct. Mater. 31, 2010426. doi:10.1002/adfm.202010426

Liu, S., Tso, C. Y., Lee, H. H., Du, Y. W., Yu, K. M., Feng, S.-P., et al. (2021b). SelfDensified Optically Transparent VO2 Thermochromic Wood Film for Smart Windows. ACS Appl. Mater. Inter. 13, 22495-22504. doi:10.1021/ acsami. $1 \mathrm{c} 03803$

Long, S., Zhou, H., Bao, S., Xin, Y., Cao, X., and Jin, P. (2016). Thermochromic Multilayer Films of WO3/VO2/WO3 sandwich Structure with Enhanced Luminous Transmittance and Durability. RSC Adv. 6, 106435-106442. doi:10.1039/c6ra23504b

Nakamura, C., Yamamoto, T., Manabe, K., Nakamura, T., Einaga, Y., and Shiratori, S. (2019). Thermoresponsive, Freezing-Resistant Smart Windows with Adjustable Transition Temperature Made from Hydroxypropyl Cellulose and Glycerol. Ind. Eng. Chem. Res. 58, 6424-6428. doi:10.1021/acs.iecr.9b00407

Nandakumar, D. K., Ravi, S. K., Zhang, Y., Guo, N., Zhang, C., and Tan, S. C. (2018). A Super Hygroscopic Hydrogel for Harnessing Ambient Humidity for Energy Conservation and Harvesting. Energ. Environ. Sci. 11, 2179-2187. doi:10.1039/c8ee00902c

Qian, X., Wang, N., Li, Y., Zhang, J., Xu, Z., and Long, Y. (2014). Bioinspired Multifunctional Vanadium Dioxide: Improved Thermochromism and Hydrophobicity. Langmuir 30, 10766-10771. doi:10.1021/la502787q

Rezaei, S. D., Shannigrahi, S., and Ramakrishna, S. (2017). A Review of Conventional, Advanced, and Smart Glazing Technologies and Materials for Improving Indoor Environment. Solar Energ. Mater. Solar Cells 159, 26-51. doi:10.1016/j.solmat.2016.08.026

Saidaminov, M. I., Abdelhady, A. L., Murali, B., Alarousu, E., Burlakov, V. M., Peng, W., et al. (2015). High-quality Bulk Hybrid Perovskite Single Crystals within Minutes by Inverse Temperature Crystallization. Nat. Commun. 6, 1-6. doi:10.1038/ncomms 8586

Schläefer, J., Sol, C., Li, T., Malarde, D., Portnoi, M., Macdonald, T. J., et al. (2019). Thermochromic VO2-SiO2 Nanocomposite Smart Window Coatings with Narrow Phase Transition Hysteresis and Transition Gradient Width. Solar Energ. Mater. Solar Cells 200, 109944. doi:10.1016/j.solmat.2019.109944

Shen, N., Chen, S., Huang, R., Huang, J., Li, J., Shi, R., et al. (2021). Vanadium Dioxide for Thermochromic Smart Windows in Ambient Conditions. Mater. Today Energ. 21, 100827. doi:10.1016/j.mtener.2021.100827

Sun, G., Cao, X., Zhou, H., Bao, S., and Jin, P. (2017). A Novel Multifunctional Thermochromic Structure with Skin comfort Design for Smart Window Application. Solar Energ. Mater. Solar Cells 159, 553-559. doi:10.1016/ j.solmat.2016.09.045

Sun, G., Zhou, H., Cao, X., Li, R., Tazawa, M., Okada, M., et al. (2016). SelfAssembled Multilayer Structure and Enhanced Thermochromic Performance of Spinodally Decomposed TiO2-VO2 Thin Film. ACS Appl. Mater. Inter. 8, 7054-7059. doi:10.1021/acsami.5b12476

Tällberg, R., Jelle, B. P., Loonen, R., Gao, T., and Hamdy, M. (2019). Comparison of the Energy Saving Potential of Adaptive and Controllable Smart Windows: A State-Of-The-Art Review and Simulation Studies of Thermochromic, Photochromic and Electrochromic Technologies. Solar Energ. Mater. Solar Cells 200, 109828. doi:10.1016/j.solmat.2019.02.041

Wang, X., Chen, L., Lu, H., Fang, W., Li, H., Yin, W., et al. (2021). Enhancing Visible-Light Transmittance while Reducing Phase Transition Temperature of VO2 by Hf-W Co-doping. Appl. Phys. Lett. 118, 192102. doi: $10.1063 / 5.0044516$

Wang, X., Hsieh, M.-L., Bur, J. A., Lin, S.-Y., and Narayanan, S. (2020a). Capillarydriven Solar-thermal Water Desalination Using a Porous Selective Absorber. Mater. Today Energ. 17, 100453. doi:10.1016/j.mtener.2020.100453

Wang, X., Hsieh, M.-L., Bur, J. A., Lin, S.-Y., and Narayanan, S. (2020b). The Role of Nanostructure Morphology of Nickel-Infused Alumina on Solar-Thermal Energy Conversion. J. Opt. 23, 015101. doi:10.1088/2040-8986/abcc53
Wang, X., Yang, H., Hsieh, M.-L., Bur, J. A., Lin, S.-Y., and Narayanan, S. (2020c). Nickel-Infused Nanoporous Alumina as Tunable Solar Absorber. MRS Adv. 5, 2575-2583. doi:10.1557/adv.2020.300

Wen, Z., Ke, Y., Feng, C., Fang, S., Sun, M., Liu, X., et al. (2021). Mg-Doped VO 2 @ZrO 2 Core-Shell Nanoflakes for Thermochromic Smart Windows with Enhanced Performance. Adv. Mater. Inter. 8, 2001606-2001609. doi:10.1002/ admi.202001606

Wheeler, L. M., Moore, D. T., Ihly, R., Stanton, N. J., Miller, E. M., Tenent, R. C. et al. (2017). Switchable Photovoltaic Windows Enabled by Reversible Photothermal Complex Dissociation from Methylammonium lead Iodide. Nat. Commun. 8. doi:10.1038/s41467-017-01842-4

Wu, L. Y. L., Zhao, Q., Huang, H., and Lim, R. J. (2017). Sol-gel Based Photochromic Coating for Solar Responsive Smart Window. Surf. Coat. Technology 320, 601-607. doi:10.1016/j.surfcoat.2016.10.074

Zhang, L., Xia, F., Yao, J., Zhu, T., Xia, H., Yang, G., et al. (2020). Facile Synthesis, Formation Mechanism and Thermochromic Properties of W-Doped VO2(M) Nanoparticles for Smart Window Applications. J. Mater. Chem. C 8, 13396-13404. doi:10.1039/d0tc03436c

Zhang, Y., Tso, C. Y., Iñigo, J. S., Liu, S., Miyazaki, H., Chao, C. Y. H., et al. (2019). Perovskite Thermochromic Smart Window: Advanced Optical Properties and Low Transition Temperature. Appl. Energ. 254, 113690. doi:10.1016/ j.apenergy.2019.113690

Zhou, H., Li, J., Bao, S., Li, J., Liu, X., and Jin, P. (2016). Use of $\mathrm{ZnO}$ as Antireflective, Protective, Antibacterial, and Biocompatible Multifunction Nanolayer of Thermochromic VO2 Nanofilm for Intelligent Windows. Appl. Surf. Sci. 363, 532-542. doi:10.1016/j.apsusc.2015.12.045

Zhou, J., Gao, Y., Zhang, Z., Luo, H., Cao, C., Chen, Z., et al. (2013). VO2 Thermochromic Smart Window for Energy Savings and Generation. Sci. Rep. 3, 1-5. doi:10.1038/srep03029

Zhou, Y., Cai, Y., Hu, X., and Long, Y. (2014). Temperature-responsive Hydrogel with Ultra-large Solar Modulation and High Luminous Transmission for "smart Window" Applications. J. Mater. Chem. A. 2, 13550-13555. doi:10.1039/c4ta02287d

Zhou, Y., Cai, Y., Hu, X., and Long, Y. (2015a). VO2/hydrogel Hybrid Nanothermochromic Material with Ultra-high Solar Modulation and Luminous Transmission. J. Mater. Chem. A. 3, 1121-1126. doi:10.1039/c4ta05035e

Zhou, Y., Dong, X., Mi, Y., Fan, F., Xu, Q., Zhao, H., et al. (2020). Hydrogel Smart Windows. J. Mater. Chem. A. 8, 10007-10025. doi:10.1039/d0ta00849d

Zhou, Z., Wang, Z., Zhou, Y., Pang, S., Wang, D., Xu, H., et al. (2015b). Methylamine-Gas-Induced Defect-Healing Behavior of CH3NH3PbI3Thin Films for Perovskite Solar Cells. Angew. Chem. Int. Ed. 54, 9705-9709. doi:10.1002/anie.201504379

Conflict of Interest: The authors declare that the research was conducted in the absence of any commercial or financial relationships that could be construed as a potential conflict of interest.

Publisher's Note: All claims expressed in this article are solely those of the authors and do not necessarily represent those of their affiliated organizations, or those of the publisher, the editors and the reviewers. Any product that may be evaluated in this article, or claim that may be made by its manufacturer, is not guaranteed or endorsed by the publisher.

Copyright $\odot 2021$ Wang and Narayan. This is an open-access article distributed under the terms of the Creative Commons Attribution License (CC BY). The use, distribution or reproduction in other forums is permitted, provided the original author(s) and the copyright owner(s) are credited and that the original publication in this journal is cited, in accordance with accepted academic practice. No use, distribution or reproduction is permitted which does not comply with these terms. 